\title{
The Impact of Government Expenditure on Growth: Empirical Evidence from a Heterogeneous Panel
}

\author{
Andros Gregoriou* and Sugata Ghosh \\ Brunel University
}

\begin{abstract}
This paper investigates the impact of government expenditure on growth, in a heterogeneous panel for 15 developing countries. Using GMM techniques, we show that countries with substantial government expenditure have strong growth effects, which vary considerably across the nations.
\end{abstract}

Keywords: Government expenditure, Economic growth, Heterogeneous panel, GMM techniques.

JEL Classification: C33, E62.

* Corresponding author. E-mail: andros.gregoriou@ brunel.ac.uk. Tel: 01895266637.

Address: Economics and Finance, Brunel University, Uxbridge, Middlesex, UB8 3PH, UK. 


\section{Introduction}

The effects of fiscal policy on the long-run rate of growth have been extensively researched within endogenous growth theory. Among the different components of fiscal policy, the impact of government expenditure on growth and welfare has been investigated in several studies (see, among others, Barro (1990)).

While much of the empirical research in the area has been in a cross-country framework (e.g., Easterly and Rebelo (1993)), there have recently been studies using panel data, which have the advantage, as pointed out by Islam (1995), that level effects for individual countries can be captured through heterogeneous intercepts (i.e., the fixed effects).

On empirical research using panel data, one can cite (among others) the papers by Devarajan et al. (1996) - henceforth DSZ - and Gupta et al. (2005) on the composition of government expenditure and growth for a sample of developing countries. DSZ found a negative (positive) and significant relationship between the capital (current) component of public expenditure and per capita real GDP growth for 43 countries over the period 1970-1990, while Gupta et al. (2005) found quite the reverse for 39 countries between 1990 and 2000.

Lee et al. (1998), commenting on Islam (1995), observe that slope heterogeneity, even when random, causes major difficulties for estimation in dynamic panels. They contend that potential heterogeneity in growth rates of different countries renders the standard fixed effects panel estimator to be biased.

Given the importance of slope heterogeneity as an econometric issue (see, among others, Baltagi (1995), and Pesaran and Smith (1995)), we extend the methodology implemented by DSZ by explicitly modelling the potential cross-country heterogeneity in capital and current expenditure. The fixed effects panel estimator used in DSZ assumes that all the slope coefficients, adjustment dynamics and error variances are invariant across all countries. However, these assumptions are unlikely to hold, because countries are not unanimous in their views on the role of government expenditure in fostering growth, and this largely depends on the political stance of the party in power. The importance assigned to capital and current expenditures, i.e., the 
commitment to spend on viable long-term capital projects vis-a-vis the spending on recurrent types of expenditure like wages and salaries, subsidies and pension arrangements, also varies across countries. The potential cross-country variations in the parameters of the level and composition of public expenditure are consequently modelled as a linear function of country-specific levels of current and capital spending in this paper.

In addition, we address the issue of endogeneity in the panel by applying the GMM system estimator, first established by Blundell and Bond (1998). Our choice of panel estimator follows Ghosh and Gregoriou (2006), who capture optimal fiscal policy in the DSZ model with the use of a GMM system technique.

The rest of the paper is organized as follows. Section 2 discusses data and the aspect of heterogeneity; Section 3 outlines specification and econometric issues; Section 4 presents empirical results, and Section 5 concludes.

\section{Data and Heterogeneity}

We use annual data on government expenditure for 15 developing countries (listed in Table 1) over 1972-1999, obtainable from the Global Development Network Growth Database, compiled by William Easterly, for our empirical analysis. We compute the mean capital expenditure and mean current expenditure (both as percentage of GDP) for these countries (see Table 1 below).

\section{[INSERT TABLE 1 HERE]}

The data in Table 1 clearly reveal the cross-country differences in the levels of capital and current expenditure for the 15 countries in our sample. For example, Sudan and Zimbabwe have the lowest average capital and current expenditure as a percentage of GDP. On the other hand, Brazil and Thailand appear to have the highest capital and current expenditure. With respect to the heterogeneity in total government expenditure, as evidenced from the data, we can see that Sudan (the country with the lowest public expenditure) spends less than 5\% of its GDP on public goods and services, whereas Brazil (the highest public expenditure country) spends more than $39 \%$ of its GDP on public expenditure. 


\section{Model Specification and Econometric Methodology}

The econometric models to be estimated are represented by (1) and (2) below. If combined, (1) and (2) would be identical to equation (13) of DSZ, which is adapted appropriately by them (page 331) to enable the fixed effects method to be applied. ${ }^{1}$

$$
\begin{aligned}
& G_{i t}=a_{i}+b_{t}+\phi\left(\frac{g_{1, i t}}{g_{1, i t}+g_{2, i t}}\right)+h\left(\frac{g_{1, i t}+g_{2, i t}}{y_{i t}}\right)+j\left(\text { shock }_{i t}\right)+l\left(b m p_{i t}\right) \\
& +e_{i t} \\
& G_{i t}=a_{i}+b_{t}+\mu\left(\frac{g_{2, i t}}{g_{1, i t}+g_{2, i t}}\right)+h\left(\frac{g_{1, i t}+g_{2, i t}}{y_{i t}}\right)+j(\text { shock })+l\left(b m p_{i t}\right) \\
& +e_{i t}
\end{aligned}
$$

where $\mathrm{i}$ and $\mathrm{t}$ denote the cross-sectional and time series dimensions respectively; $\mathrm{a}_{\mathrm{i}}$ captures the time-invariant unobserved country-specific fixed effects and $b_{t}$ captures the unobservable individual-invariant time effects. $G$ is the per capita real GDP growth rate, $\mathrm{g}_{1}$ is 'capital expenditure', and $\mathrm{g}_{2}$ is 'current expenditure', both from the 'Government Finance' account in the Easterly database, y is GDP at market prices, the 'shock' variable is constructed as in DSZ, and the 'bmp' is the black market premium as defined in DSZ.

The specification represented by equations (1) and (2) allows only for unobservable individual and time effects. All other parameters are assumed homogeneous across all countries in the panel. In order to allow for heterogeneity in the parameters of the panel, we model cross-country heterogeneity in capital and current expenditure directly by estimating the following models:

$$
\begin{aligned}
& G_{i t}=a_{i}+b_{t}+\lambda\left(\phi_{i t} * \bar{g}_{1, i}\right)+\delta_{1}\left(h_{i t} * \bar{g}_{1, i}\right)+j\left(\text { shock }_{i t}\right)+l\left(b m p_{i t}\right) \\
& +e_{i t} \\
& G_{i t}=a_{i}+b_{t}+\gamma\left(\mu_{i t} * \bar{g}_{2, i}\right)+\delta_{2}\left(h_{i t} * \bar{g}_{2, i}\right)+j\left(\text { shock }_{i t}\right)+l\left(\text { bmp }_{i t}\right) \\
& +e_{i t}
\end{aligned}
$$

\footnotetext{
${ }^{1}$ We do not combine (1) and (2) - this is similar to DSZ - because of possible collinearity among regressors.
} 
where $\bar{g}_{1, i}=T_{i}^{-1} \sum_{i=1}^{T_{i}} g_{1, i t}$ and $\bar{g}_{2, i}=T_{i}^{-1} \sum_{t=1}^{T_{i}} g_{2, i t}$, and the other variables are as previously defined. Equations (3) and (4) represent the heterogeneous panel model. They allow the slope parameters $(\lambda, \gamma, \delta)$ of the capital and current expenditure to vary across countries. Heterogeneity in parameters are assumed to be a linear function of country-specific mean levels of capital and current expenditure $\left(\bar{g}_{1, i}\right.$ and $\left.\bar{g}_{2, i}\right)$. From (3) and (4), the respective country-specific parameters for capital and current expenditure are computed as:

$$
\omega_{1}=\left(\lambda * \bar{g}_{1, i}\right) ; \quad \omega_{2}=\left(\gamma * \bar{g}_{2, i}\right)
$$

As previously mentioned, in order to capture the cross-country heterogeneity in equations (3) and (4), we use the system GMM estimator, unlike DSZ, who use the OLS estimator. This econometric methodology makes use of lagged instruments of the endogenous variables for each time period to tackle possible endogeneity of the explanatory variables in the panel. Although the GMM single equation estimator developed by Arellano and Bond (1991) also performs a similar task, it suffers from the problem of weak correlation between the regressors and the instruments when the time-series dimension of the panel is fairly small.

The consistency of the GMM system hinges crucially on whether the lagged values of the explanatory variables are a valid set of instruments, and whether $e_{i t}$ is not serially correlated. We undertake the Difference-Sargan test to establish the validity of the instrument set. A first order serial correlation test is performed to test whether the error term suffers from serial correlation.

\section{Empirical Results}

Table 2 reports the results obtained for the heterogeneous panel data model specified in equations (3) and (4). The parameters that are associated with the variables that interact with $\bar{g}_{1, i}$ and $\bar{g}_{2, i}$ are all highly significant, implying significant cross-country variations. Therefore, the parameters of economic growth are country-specific and depend upon the levels of capital and current expenditure of each nation. The models 
reported in Table 2 pass all the diagnostic tests. The fixed and time effects of the panels appear significant, implying that the country and time specific shocks differ significantly across the countries in our sample. Also, the test for first order residual serial correlation is insignificant, which shows that the panels do not suffer from serial correlation. The results from the Sargan tests confirm the validity of the instruments in the GMM system. ${ }^{2}$

\section{[INSERT TABLE 2 HERE]}

Table 3 reports the country-specific capital and current expenditure parameters computed from the results in Table 2 , following the methodology of equation (5). The capital (current) expenditure parameter shows a negative (positive) effect with respect to economic growth for all countries; however, there is pronounced cross-country variation. The capital expenditure parameter ranges from -0.62 (Sudan) to -1.30 (Brazil); a difference of 2.10 times. The cross-sectional variation is also observed for current expenditure, for which the parameter ranges from a minimum of 1.11 (Sudan) to a maximum of 16.26 (Brazil); a difference of 14.6 times. The cross-sectional variation amongst the countries in our sample is clearly more apparent for current expenditure, and this is due to the higher proportion of current expenditure in total public expenditure in all countries (see Table 1$)^{3}$

\section{[INSERT TABLE 3 HERE]}

\section{Conclusion}

In this paper, we explicitly modelled the potential cross-country heterogeneity in capital and current expenditure on economic growth, in a panel framework consisting of 15 developing countries over a period of 28 years. Unlike DSZ and Gupta et al. (2005), the heterogeneity was modelled as a function of country-specific mean levels of capital and current expenditure. We applied the GMM system estimator in order to

\footnotetext{
${ }^{2}$ The dependent variable chosen by DSZ is the five-year forward moving average of the per capita real GDP growth rate. This is chosen to eliminate short-term fluctuations, and also the possibility of reverse causality. Therefore, for robustness we also estimated our empirical models using the five-year moving average. The results (not reported, but available upon request) do not change.

${ }^{3}$ One potential shortcoming with the use of the GMM estimator is that the properties hold when the number of countries is large. Therefore, the GMM system estimator may be biased and imprecise in our sample, given that we only have 15 countries. An alternative approach to the GMM system estimator for small samples is the fixed effects estimator corrected for small sample bias, devised by Kiviet (1995). For robustness, we re-estimate Tables 2 and 3 using the Kiviet (1995) estimator, and the GMM results hold, even though we only have 15 countries. These results (not reported) are available upon request.
} 
address the issues of endogeneity, weak instruments and measurement errors. We showed that these measures capture effectively the cross-country variations in the parameters of the model, which suggest that for nations such as Brazil, current expenditures have a major role to play in determining long-run growth, whereas for countries like Sudan, current expenditure plays only a minor role in the growth of the nation. 


\section{References}

Arellano, Manuel and Stephen R. Bond (1991). "Some Tests of Specification for Panel Data: Monte Carlo Evidence and an Application to Employment Equations." Review of Economic Studies, Vol. 58, 277-297.

Baltagi Badi H. (1995). Econometric Analysis of Panel Data, John Wiley \& Sons, New York.

Barro, Robert J. (1990). 'Government Spending in a Simple Model of Endogenous Growth,' Journal of Political Economy, Vol. 98, S103-S125.

Blundell, Richard and Stephen R. Bond (1998). "Initial Conditions and Moment Restrictions in Dynamic Panel Data Models.” Journal of Econometrics, Vol. 87, 115-143.

Devarajan, Shantayanan, Vinaya Swaroop, and Heng-fu Zou (1996). 'The Composition of Public Expenditure and Economic Growth, Journal of Monetary Economics, Vol. 37, 313344.

Easterly, William, Global Development Network Growth Database,

Development Research Institute, New York University (website: http://www.nyu.edu/fas/institute/dri/global\%20development\%20network\%20growth\%20data base.htm)

Easterly, William and Sergio Rebelo (1993). Fiscal Policy and Economic Growth: An Empirical Investigation, Journal of Monetary Economics, Vol. 32, 417-458.

Ghosh, Sugata, and Andros Gregoriou (2006). 'On the Composition of Government Spending, Optimal Fiscal Policy, and Endogenous Growth: Theory and Evidence', Brunel Economics and Finance Working Paper 06-19.

Gupta, Sanjeev, Benedict Clements, Emanuele Baldacci, and Carlos Mulas-Granados (2005). 'Fiscal Policy, Expenditure Composition, and Growth in Low-Income Countries', Journal of International Money and Finance, Vol. 24, 441-463.

Islam, Nazrul (1995). 'Growth Empirics: A Panel Data Approach', Quarterly Journal of Economics, Vol. 110, 1127-1170.

Kiviet, Jan F. (1995), "On Bias, Inconsistency and Efficiency of Various Estimators in Dynamic Panel Data Models", Journal of Econometrics, Vol. 68, 53-78.

Lee, Kevin, M. Hashem Pesaran, and Ron Smith (1998). 'Growth Empirics: A Panel Data Approach - A Comment', Quarterly Journal of Economics, Vol. 113, 319-323.

Pesaran, M. Hashem, and Ron Smith (1995). 'Estimating Long-Run Relationships from Dynamic Heterogeneous Panels', Journal of Econometrics, Vol. 68, 79-113. 


\section{TABLES}

TABLE 1: Heterogeneity in the data on public expenditure across countries

\begin{tabular}{|ccc|}
\hline Country & $\begin{array}{c}\text { Mean Capital Expenditure (\% } \\
\text { of GDP) }\end{array}$ & $\begin{array}{c}\text { Mean Current Expenditure (\% of } \\
\text { GDP) }\end{array}$ \\
Sudan & 1.94 & 2.41 \\
Zimbabwe & 2.25 & 4.71 \\
Pakistan & 2.29 & 6.47 \\
Malaysia & 2.38 & 9.45 \\
Kenya & 2.76 & 13.21 \\
Cameroon & 2.79 & 14.75 \\
Tanzania & 3.00 & 16.76 \\
Columbia & 3.22 & 17.27 \\
Mexico & 3.33 & 18.58 \\
Chile & 3.41 & 19.57 \\
Indonesia & 3.57 & 29.64 \\
Argentina & 3.70 & 31.41 \\
India & 3.75 & 33.78 \\
Thailand & 3.94 & 35.17 \\
Brazil & 4.05 & 35.34 \\
\hline
\end{tabular}


TABLE 2: Heterogeneous panel estimates of the contribution of the capital component and current component of public expenditure

\begin{tabular}{llll} 
CAPITAL & & CURRENT & \\
\hline Parameter & GMM System & Parameter & GMM System \\
\hline Constant & $22.24(\mathbf{2 . 4 9})^{*}$ & constant & $23.65(\mathbf{2 . 5 9})^{*}$ \\
$\lambda$ & $-0.32(-\mathbf{- 2 . 7 8})^{*}$ & $\gamma$ & $0.46(\mathbf{2 . 9 9})^{*}$ \\
$\delta_{1}$ & $0.58(\mathbf{2 . 9 1})^{*}$ & $\delta_{2}$ & $0.49(\mathbf{2 . 8 2})^{*}$ \\
$j$ & $0.112(\mathbf{0 . 9 4})$ & $j$ & $0.131(\mathbf{0 . 9 6})$ \\
$l$ & $-0.213(-\mathbf{- 2 . 0 1})^{*}$ & $l$ & $-0.233(-\mathbf{- 2 . 0 0})^{*}$ \\
$\mathrm{a}_{\mathrm{i}}$ & $(0.00)$ & $\mathrm{a}_{\mathrm{i}}$ & $(0.00)$ \\
$\mathrm{b}_{\mathrm{t}}$ & $(0.00)$ & $\mathrm{b}_{\mathrm{t}}$ & $(0.00)$ \\
$\mathrm{SE}$ & 0.126 & $\mathrm{SE}$ & 0.126 \\
$\mathrm{AR}(1)$ & $(0.424)$ & AR(1) & $(0.433)$ \\
Diff-Sargan & $(0.56)$ & Diff-Sargan & $(0.58)$ \\
NORM $(2)$ & 0.180 & NORM $(2)$ & 0.180 \\
Observations & 267 & Observations & 267 \\
\hline
\end{tabular}

$\mathrm{AR}(1)$ is the first order Lagrange Multiplier test for residual serial correlation. SE represents the standard error of the panel estimator. Under the GMM system, this test is undertaken on the first difference of the residuals because of the transformations involved. $a_{i}$ and $b_{t}$ are the fixed and time effects. Sargan tests follow a $\chi^{2}$ distribution with $r$ degrees of freedom under the null hypothesis of valid instruments. NORM (2) is the p-value for the Jarque-Bera normality test. The endogenous explanatory variables in the panel are GMM instrumented setting $z \geq 3$. (.) are $\mathrm{p}$ values, (.) are $\mathrm{t}$ statistics, * indicate significant at all conventional levels.

TABLE 3: Country-specific parameters obtained from the estimates of Table 2

\begin{tabular}{|ccc|}
\hline Country & Capital Expenditure & Current Expenditure \\
& $\left(\omega_{1}\right)$ & $\left(\omega_{2}\right)$ \\
Sudan & -0.62 & 1.11 \\
Zimbabwe & -0.72 & 2.16 \\
Pakistan & -0.73 & 2.98 \\
Malaysia & -0.76 & 4.35 \\
Kenya & -0.88 & 6.08 \\
Cameroon & -0.90 & 6.78 \\
Tanzania & -0.96 & 7.71 \\
Columbia & -1.03 & 7.95 \\
Mexico & -1.06 & 8.55 \\
Chile & -1.09 & 9.00 \\
Indonesia & -1.14 & 13.63 \\
Argentina & -1.18 & 14.45 \\
India & -1.20 & 15.54 \\
Thailand & -1.26 & 16.18 \\
Brazil & -1.30 & 16.26 \\
\hline
\end{tabular}

